\title{
Livestock grazing and trampling effects on plant functional composition at three wells in the desert steppe of Mongolia
}

\author{
Amartuvshin Narantsetseg ${ }^{1}$, Sinkyu Kang $^{2^{*}}$ (D) and Dongwook Ko ${ }^{3}$
}

\begin{abstract}
Backgrounds: In arid grasslands, wells are subject to heavy trampling and grazing pressure, which can increase vulnerability to local land degradation. To investigate trampling and grazing, we surveyed plant communities at three well sites in the desert steppe of Mongolia, using 1600-m line transects from the wells. The sites (Bshrub, Sshrub, and shrubL) differed by concomitant shrub type (big shrub, small shrub, and shrub-limited) and livestock pressure (light, medium, and heavy). A plant classification scheme based on edibility and morphology (rosette or creeping type) was used to separate grazing and trampling effects on plant communities.

Results: Edible plants were dominant at all sites but a fraction of grazing- and trampling-tolerant plants increased in the order Bshrub, Sshrub, and shrubL, following livestock pressure. Clear transition zones from inedible to edible plant groups were recognized but at different locations and ranges among the sites. Trampling-tolerant plants explained $90 \%$ of inedible plants at Sshrub with camels and horses, but grazing-tolerant plants prevailed (60\%) at shrubL with the largest livestock number. Plant coverage increased significantly along the transects at Bshrub and Sshrub but showed no meaningful change at shrubl. Herbaceous plant biomass showed significant positive and negative trends at Bshrub and shrubL, respectively.
\end{abstract}

Conclusions: Both grazing and trampling can produce larger fractions of inedible plants; in this, camel and horses can have considerable effects on desert-steppe plant communities through trampling.

Keywords: Mongolia, Desert steppe, Well, Livestock grazing and trampling, Plant community

\section{Background}

On the Mongolian plateau, one of the largest biomes with arid and semiarid environments in Asia, the water resource is a critical component for sustainable nomadism. In arid grasslands, though climate-driven, inter-annual variations of plant biodiversity and biomass are strong (Fernandez-Gimenez and Allen-Diaz 1999; Stumpp et al. 2005), it is also clear that livestock have critical impacts on plant communities and locally participate in pasture land degradation (Fujita and Amartuvshin 2012). Because the daily feeding distance of livestock is generally constrained to a few kilometers in Mongolia (Cérénhand 2005), livestock impacts can produce finer-scale pasture heterogeneity of plant

\footnotetext{
* Correspondence: kangsk@kangwon.ac.kr

${ }^{2}$ Department of Environmental Science, Kangwon National University,

Chuncheon 200-701, Republic of Korea

Full list of author information is available at the end of the article
}

composition and standing biomass than that caused by regional climate gradients (Narantsetseg et al. 2014; Narantsetseg et al. 2015).

The impacts of livestock through grazing and trampling vary considerably in space and time and depend on regional nomadic styles and livestock composition. Various compositions of livestock and plant communities make livestock-plant interactions more complex. For example, concomitant shrubs are an alternative feeding resource (Fujita and Amartuvshin 2012), and large livestock can have heavy grazing and trampling effects. It is, however, not well understood whether grazing and trampling have similar or different effects on plant composition and how strong their impacts are along the gradient of livestock pressure in the arid grasslands. It is also unclear how concomitant edible shrubs (such as Caragana spp.) and large livestock (e.g., camels and horses) affect the livestock-plant interactions. Because of

(c) The Author(s). 2018 Open Access This article is distributed under the terms of the Creative Commons Attribution 4.0 International License (http://creativecommons.org/licenses/by/4.0/), which permits unrestricted use, distribution, and 
their sparse distributions, wells are subject to intensive use in livestock herding within arid regions, so they furnish a useful framework to investigate questions on such interactions (Fernandez-Gimenez and Allen-Diaz 1999; Sasaki et al. 2005; Stumpp et al. 2005).

A well is a primary water source for the livelihood of local herders in the desert steppe, where livestock pressure is generally much greater than that in remote pasture. Herbivores have strong direct and indirect effects on plant communities and production through grazing, browsing, trampling, defecation, and urination (Mysterud 2006). Grazing-tolerant plants generally dominate near water sources and winter camps, whereas edible species are dominant far from such places (Sasaki et al. 2005; Jambal 2013). Similarly, Fernandez-Gimenez and Allen-Diaz (1999) reported that plant composition varied from grazing-tolerant to edible herbaceous plants and shrubs with distance from wells. In arid grasslands, shrubs can disperse grazing pressure on herbaceous plants. Deep-rooted shrubs (e.g., Caragana spp.) or succulent small shrubs (e.g., Eurotia ceratoides and Artemisia schischkinii) are important foraging resources for livestock during dry seasons (Jigjidsuren and Johnson 2003; Fujita et al. 2012). Inedible shrubs (e.g., E. ceratoides) dominate near water (Stumpp et al. 2005), while edible Caragana spp. and Artemisia schischkinii are more frequent far from water sources (Fernandez-Gimenez and Allen-Diaz 1999).

Together with grazing, trampling can influence the composition of an herbaceous plant community (Morinaga et al. 2016; Mudongo et al. 2016). With trampling, short- (rosette or creeping types) or thick-stem plants tend to dominate (Xu et al. 2013). Strong trampling-tolerant plants are caespitose, matted and rosette hemicryptophytes (buds at or near the soil surface), and geophytes (rhizome, stem-tuber, root-tuber, bulb, and others), whereas chamaephytes (e.g., dwarf- or semi-shrub) are weak against trampling disturbance (Cole 1995). Because studies have indicated that trampling can result in greater abundance of trampling-tolerant plants, in situ abundance of such plants can be a proxy of trampling pressure in grasslands.

This study aimed to examine how grazing and trampling disturbances are reflected in plant communities and their variation with distance from wells at three desert-steppe sites in Mongolia. The dominance of grazing- and trampling-tolerant plants was used as proxies of grazing and trampling pressures, respectively. Field surveys were conducted at three well sites with different plant communities and livestock number and composition. The roles of concomitant shrubs and fractions of large livestock were analyzed in regulating plant composition and biomass along transects.

\section{Methods}

\section{Study area and data collection}

The Mongolian steppe has distinct latitudinal patterns, from northern forest steppe to central typical and southern desert steppes with dryness (Fujita et al. 2012). The three well sites selected in the study were in a transition zone (i.e., desert steppe) between northern typical steppe and the southern Gobi desert in Bayankhongor aimag (province) of Mongolia. Each site can be characterized by different shrub types, namely, big-shrub (Bshrub) $\left(45^{\circ} 36^{\prime}\right.$ $\left.18^{\prime \prime}, 100^{\circ} 46^{\prime} 29^{\prime \prime}\right)$, small-shrub (Sshrub) $\left(45^{\circ} 12^{\prime} 23^{\prime \prime}, 101^{\circ}\right.$ $06^{\prime} 34^{\prime \prime}$ E), and shrub-limited (shrubL) $\left(45^{\circ} 27^{\prime} 28^{\prime \prime} \mathrm{N}, 101^{\circ}\right.$ 07'12" E) (Fig. 1a). The big- and small-shrub sites were
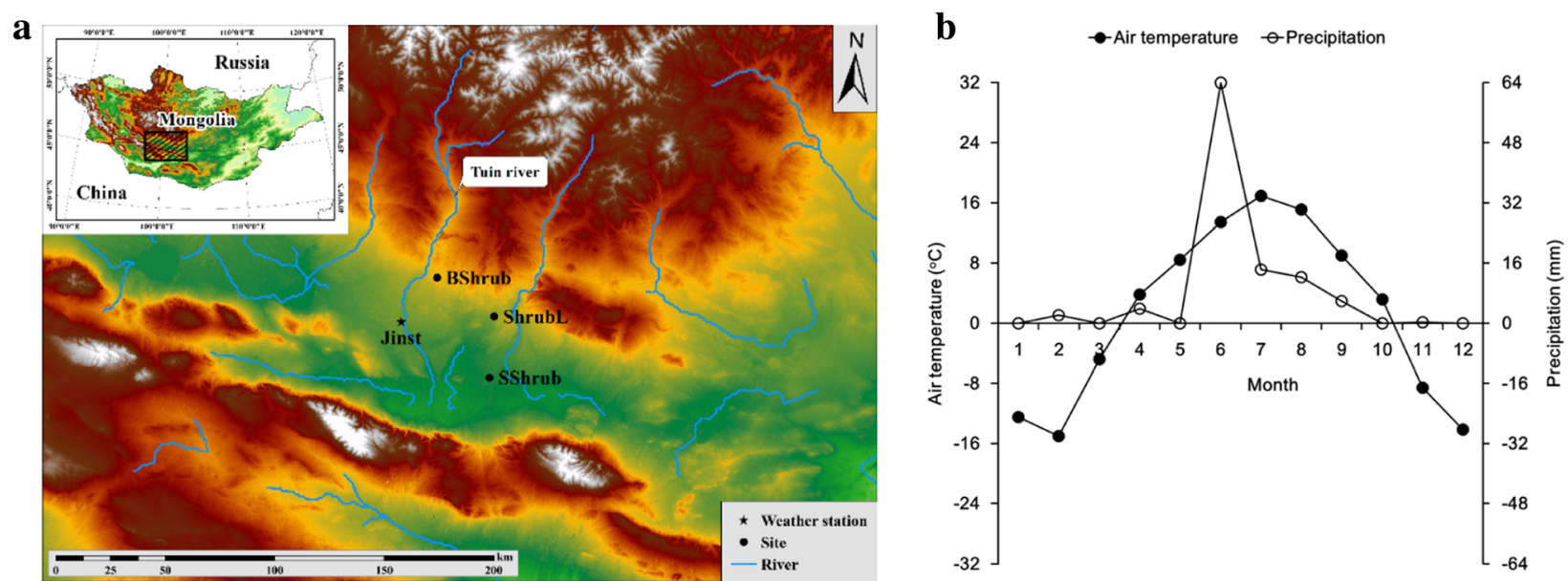

Fig. 1 Locations of study sites (a) and monthly temperature and precipitation in 2014 (b). The keymap illustrates Mongolian territory and the study region. The monthly climate data were observed at the nearest weather station in Jinst, Bayanhongor. The climate data were collected by the Institute of Meteorology and Hydrology, Mongolian Academy of Sciences 
dominated by Caragana spp. and Ajania spp., respectively. Shrubs rarely appeared at the shrub-limited site.

The long-term averages in temperature and precipitation observed from the nearest weather station from our sites were $+3.5{ }^{\circ} \mathrm{C}$ and $75.5 \mathrm{~mm}$, respectively. The year 2014 was cooler $\left(+1.2^{\circ} \mathrm{C}\right)$ and wetter $(102.4 \mathrm{~mm})$ than normal. Air temperature varied from $-15{ }^{\circ} \mathrm{C}$ in February to $17{ }^{\circ} \mathrm{C}$ in July (Fig. 1b). Until May, it was dry with less than $5 \mathrm{~mm}$ of monthly precipitation but followed by high monthly precipitation, 64 and $14 \mathrm{~mm}$, in June and July, respectively.

The site characteristics also differed by livestock number and composition. Bshrub and Sshrub were similar in ger (Mongolian herder's nomadic residence) and livestock numbers but had different livestock compositions. In contrast, shrubL had more ger and livestock numbers. There were 3, 3, and 10 gers which are herder family houses within a $3-\mathrm{km}$ radius from the wells, and approximately 600, 650, and 1500 heads at Bshrub, Sshrub, and shrubL, respectively. Livestock were mostly sheep and goats except for Sshrub, which had some camels and horses ( 8 and 30 heads, respectively). In sheep units, per-head grazing pressure of camels and horses were five and seven times greater than that of per-head sheep, respectively (Bedunah and Schmidt 2000).

A vegetation survey was performed in July 2014. Species dominance was recorded at every $100-\mathrm{m}$ interval site away from the well, up to $1600 \mathrm{~m}$. Each transect started from the well and headed toward the opposite direction of ger. Each interval site has triple replicate plots of $1 \times 1 \mathrm{~m}^{2}$ at a $10-\mathrm{m}$ interval along the transect.

For each plot, species names of primary and sub-dominant plants were recorded, respectively, together with total plant coverage. The dominance and coverage measures were based on the Braun-Blanquet scale (van der Maarel 1979). For the triple replicates, therefore, six species were named, sometimes redundantly, as either primary or sub-dominant plants. The total plant coverage was averaged for the triple replicates, whereas, redundancy of each dominant species was counted and used to estimate relative importance values (RIV) of each dominant species. For example, if Stipa gobica appeared dominantly at two of three replicates, RIV was $33 \%$.

To examine the response of plant community to livestock grazing and trampling effects, the primary and sub-dominant species were grouped into different plant functional types (PFTs), as explained in the following section. Similar to the dominant species, the redundancy of the each PFT was counted for the triple replicates and used to calculate the RIV (\%) of each PFT. The two kinds of relative importance values (\%) for the dominant species and plant functional types were used to examine how dominant species and plant functional type vary along the distance from well.
In addition, we observed signs of livestock dung and collected aboveground herbaceous biomass samples along each transect. The aboveground biomass was averaged but livestock dung signs were counted for the triple replicate plots, respectively. The aboveground biomass samples were collected for Bshrub and ShrubL sites only because of rainy field condition in Sshrub site. The aboveground biomass was clipped at the soil surface, with three replicates of $0.5-\mathrm{m}^{2}$ circle plots at 8-9 surveying sites along each transect. These were then oven-dried for $48 \mathrm{~h}$ at $80{ }^{\circ} \mathrm{C}$ in the laboratory to measure dry biomass.

\section{Vegetation classification}

To analyze grazing and trampling effects, pasture plants were separated into multiple groups based on edibility and trampling tolerance (Jigjidsuren and Johnson 2003). The edible plants were further separated into three types, edible herbaceous (EH), small shrub (SS), and big shrub (BS). All shrubs are edible at the study sites. In particular, new branches and leaves are an effective feeding resource for livestock (Jigjidsuren and Johnson 2003). Grazing-tolerant plants (GT) were also further divided into two types, short-height grazing escapes (GE) and tall grazing-tolerant herbaceous (GTH) species. Consequently, we analyzed plant composition based on five vegetation types (EH, GE, GTH, SS, and BS), contrasting edible vs. inedible, herbaceous vs. shrub, and escape or non-escape.

Among the vegetation types, GE represents the case of inedible plants escaping from grazing by low height, such as creeping, rosettes, and short culms (Fujita et al. 2002). These have often been regarded as trampling-resistant plants (Xu et al. 2013). Hence, we evaluated trampling effects at our study sites using the presence of GE plants. The nomenclature follows Grubov (2001). Spearman's rank correlation was used to calculate correlation between coverage/biomass and distance from wells, and the Tukey HSD test was used to compare total coverage, height, and biomass within and between transects.

\section{Results}

\section{Species composition}

Dominant and sub-dominant herbaceous plant composition varied with well site (Table 1). At all sites, recognizable plant coverage appeared $20-30 \mathrm{~m}$ from the wells. At all sites, Stipa spp., an edible species, was the most dominant plant, though its spatial distribution differed by site. In the vicinity of wells (out to 200-300 m), different species (Allium spp., Convolvulus ammanii, and Peganum nigellastrum) were dominant at the Bshrub, Sshrub, and shrubL sites, respectively. At Sshrub and shrubL, there was a distinct transition of plant composition from Convolvulus ammanii and Peganum 
Table 1 Primary dominant plant species and their plant functional type (PFT) and relative importance value (RIV, \%) along well transects

\begin{tabular}{llll}
\hline Distance $(\mathrm{m})$ & Bshrub (PFT, RIV) & Sshrub (PFT, RIV) & shrubL (PFT, RIV) \\
\hline $0-20$ & - & Convolvulus ammanii (GE, 50\%) & Peganum nigellastrum (GT, 50\%) \\
$100-120$ & Allium mongolicum (EH, 17\%) & Stipa gobica (EH, 33\%) & Peganum nigellastrum (GT, 50\%) \\
& Allium polyrrhizum (EH, 50\%) & Convolvulus ammanii (GE, 50\%) & Peganum nigellastrum (GT, 33\%) \\
$200-220$ & Allium polyrrhizum (EH, 33\%) & Convolvulus ammanii (GE, 33\%) & Stipa glareosa (EH, 33\%) \\
$300-320$ & Allium polyrrhizum (EH, 33\%) & Stipa gobica (EH, 50\%) & Iris bungei (EH, 33\%) \\
$400-420$ & Cleistogenes soongorica (EH, 50\%) & Stipa gobica (EH, 50\%) & Stipa glareosa (EH, 50\%) \\
$500-520$ & Stipa glareosa (EH, 33\%) & Stipa gobica (EH, 50\%) & Stipa glareosa (EH, 50\%) \\
$600-620$ & Convolvulus ammanii (GE, 33\%) & Stipa gobica (EH, 50\%) & Stipa glareosa (EH, 33\%) \\
$700-720$ & Agropyron cristatum (EH, 33\%) & Stipa gobica (EH, 50\%) & Stipa glareosa (EH, 50\%) \\
$800-820$ & Agropyron cristatum (EH, 33\%) & Stipa gobica (EH, 50\%) & Stipa glareosa (EH, 50\%) \\
& Cleistogenes squarrosa (EH, 33\%) & & Stipa glareosa (EH, 50\%) \\
$900-920$ & Stipa glareosa (EH, 50\%) & Stipa gobica (EH, 50\%) & Stipa glareosa (EH, 50\%) \\
$1000-1020$ & Cleistogenes soongorica (EH, 50\%) & Stipa gobica (EH, 50\%) & Stipa glareosa (EH, 60\%) \\
$1100-1120$ & Stipa glareosa (EH, 50\%) & Stipa gobica (EH, 50\%) & Stipa glareosa (EH, 50\%) \\
$1200-1220$ & Stipa glareosa (EH, 50\%) & Stipa gobica (EH, 50\%) & Stipa glareosa (EH, 50\%) \\
$1300-1320$ & Stipa glareosa (EH, 33\%) & Stipa gobica (EH, 50\%) & Stipa glareosa (EH, 50\%) \\
$1400-1420$ & Stipa glareosa (EH, 33\%) & Stipa gobica (EH, 50\%) & Stipa glareosa (EH, 50\%) \\
$1500-1520$ & Stipa glareosa (EH, 50\%) & Stipa gobica (EH, 50\%) & Stipa gobica (EH, 50\%) \\
$1600-1620$ & Stipa glareosa (EH, 17\%) & &
\end{tabular}

nigellastrum to Stipa spp. in the 200-300-m range, respectively. Convolvulus ammanii and Peganum nigellastrum explained RIVs from 33 to $50 \%$ within $200 \mathrm{~m}$, while Stipa gobica and Stipa glareosa did over 300 m, respectively. At Bshrub, however, there was a relatively wide transition range (between 400 and $1000 \mathrm{~m}$ ) from Allium spp. to Stipa glareosa, where Stipa glareosa co-dominated with Cleistogenes soongorica, Convolvulus ammanii, and Agropyron cristatum. Shrubs were frequent from the middle of the transect $(\sim 600 \mathrm{~m})$ but were very limited near the wells at both Bshrub and Sshrub.

Among the plant groups, $\mathrm{EH}$ dominates the others as the primary and sub-dominant plant group at all sites, with occurrence rates of 83,55 , and $81 \%$ at Bshrub, SSshrub, and shrubL, respectively. The rate of GT was highest at Sshrub (33\%), followed by shrubL (18\%) and Bshrub (5\%), the order of which was same as GE, i.e., 29, 8 , and $0 \%$, respectively. Though GT plants were observed frequently at Sshrub, their dominance was confined to the vicinity of wells at Bshrub and shrubL (Fig. 2). GE was common along the transect of Sshrub and more abundant near the well $(<800 \mathrm{~m})$ at shrubL, but it was rare at Bshrub (Fig. 2d).

\section{Coverage, height, and biomass}

Means and spatial variability of plant coverage, height, and biomass differed by well site. Overall, those biotic variables were greater at Bshrub than those at the others. Bshrub had significantly $(p<0.01)$ denser coverage and greater spatial variability $(11.6 \pm 5.0 \%)$ than Sshrub $(6.3$ $\pm 2.8 \%)$ or shrubL $(6.2 \pm 1.3 \%)$. Plant maximum height was significantly greater $(p<0.01)$ at Bshrub $(23.5 \pm$ $12.6 \mathrm{~cm})$, followed by shrubL $(17.6 \pm 6.1 \mathrm{~cm})$ and Sshrub $(13.3 \pm 3.1 \mathrm{~cm})$. In contrast, minimum heights did not significantly vary, within a range from 1.1 to $1.6 \mathrm{~cm}$. Transect-mean biomass was greater at Bshrub $(6.8 \pm 3.0)$ than that at shrubL $(4.0 \pm 1.4)$, but this was not significant $(p=0.24)$.

Spatial patterns of the observed variables were distinct along the transects (Fig. 3). Most variables showed increasing trends but with considerable variation. Sshrub showed significant $(<0.01)$ positive trends in coverage and maximum and minimum heights. At Bshrub, significant positive trends $(p<0.01)$ were found only for biomass and maximum height. At shrubL, biomass was the only variable with a meaningful trend (slope $=-0.002$, $p=0.09)$. In the vicinity of wells $(\sim 300 \mathrm{~m})$, some site variables showed clear positive trends, i.e., Bshrub and shrubL coverages $(r=0.95, p=0.05$ and $0.97, p=0.03)$, Sshrub maximum heights $(r=1.0, p<0.01)$, and Bshrub biomass $(r=0.93, p=0.07)$ out to $300 \mathrm{~m}$. The range of those positive trends was generally coincident with the transition range of dominant plants at each well site (Table 1).

Among the observed variables, several meaningful correlations were found. For Bshrub, biomass was strongly 

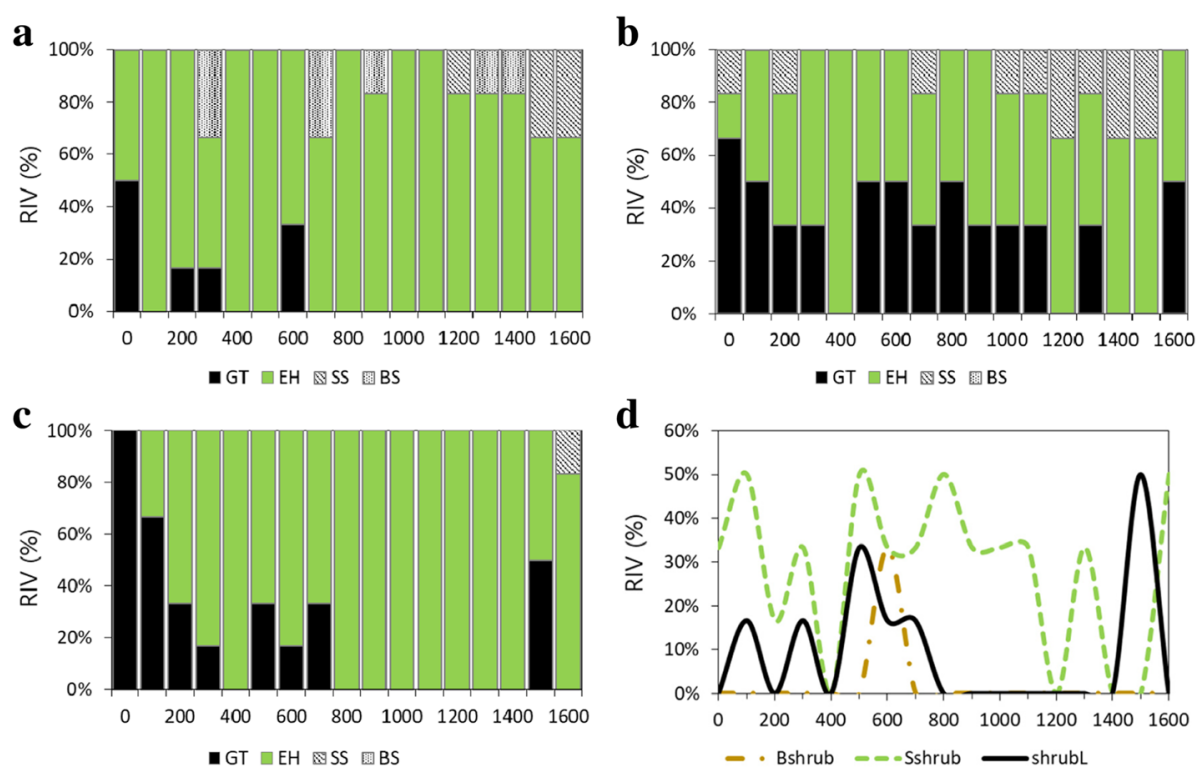

Fig. 2 Occurrence rates (\%) of primary and sub-dominant species along transects for each plant group: a Bshrub, b Sshrub, and c shrubL; d percentage of escaper plants (GE)

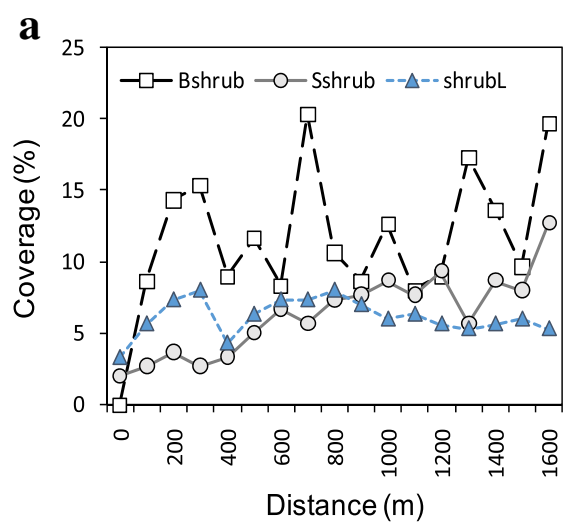

c

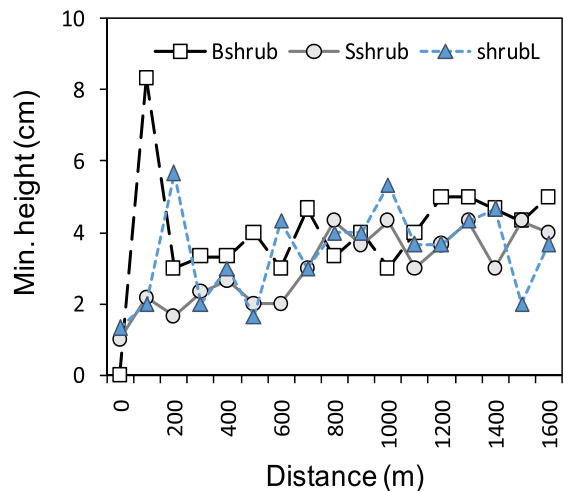

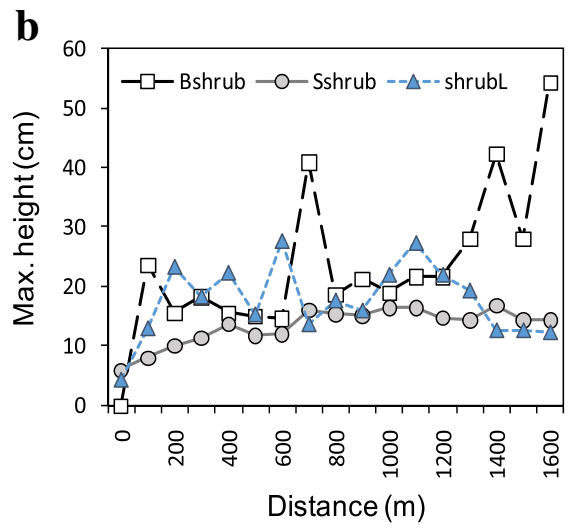

d

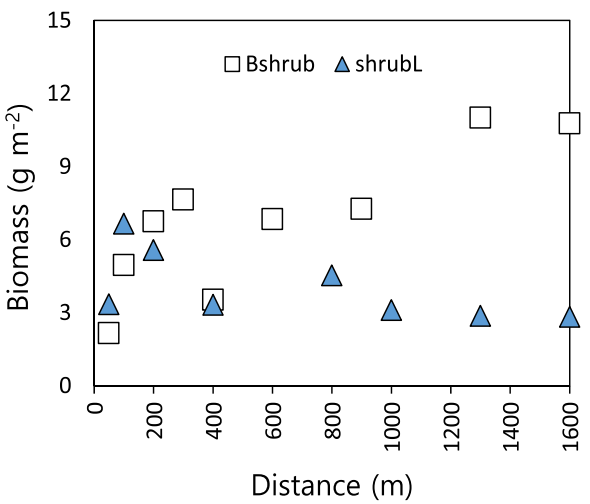

Fig. 3 Spatial patterns of a total plant coverage (\%), b maximum height $(\mathrm{cm}), \mathbf{c}$ minimum height $(\mathrm{cm})$, and $\mathbf{d}$ dry aboveground biomass $\left(\mathrm{g} \mathrm{m}^{-2}\right.$ ) along well transects at study sites big-shrub (Bshrub), small-shrub (Sshrub), and shrub-limited (shrubL) 
correlated with coverage $(r=0.82, p<0.05)$ and maximum height $(0.68, p=0.065)$, whereas shrubL biomass was poorly correlated with coverage and height variables. There were significant positive correlations between coverage and height variables $(r=0.71-0.75, p<0.01)$ for Bshrub and Sshrub. Again, shrubL coverage did not show meaningful correlations with plant heights. The above results indicate that the various biotic variables had strong correlation at Bshrub and Sshrub but not at shrubL.

Dung was observed more frequently at shrubL than Bshrub and Sshrub. Across the transects, it was concentrated near wells (within $300 \mathrm{~m}$ ) and showed clear deceasing trends with distance at all sites $(p<0.05)$. In contrast with Bshrub and shrubL, horse dung was observed overwhelmingly at Sshrub (Fig. 4).

\section{Discussion}

Together with grazing, livestock trampling should be an important factor in determining plant composition (Morinaga et al. 2016; Mudongo et al. 2016). Even after trampling disturbance, Allium spp., Convolvulus ammanii, and Peganum nigellastrum can regrow by bulbous, short rootstock and stolon (Jigjidsuren and Johnson 2003), indicating strong tolerance to substantial livestock trampling. In our results, recognizable plant coverage of those trampling-tolerant species up to $200-300 \mathrm{~m}$ from the wells reveals strong trampling effects there at all sites. Additionally, the broad distribution of such species at Sshrub implies greater trampling impacts of large livestock (camels and horses) than that of sheep and goats, as suggested by Bruegger et al. (2014). Trampling-tolerant plants made up $90 \%$ of inedible plants at Sshrub but remained $40 \%$ at shrubL, where both trampling and grazing impacts combined to increase inedible plants. Fujita et al. (2002) reported that species numbers of EH, GE, and GTH indicated light, moderate, and heavy grazing pressure, respectively, in the forest-steppe zone of Mongolia. Following their criteria, our three study sites, Bshrub, Sshrub, and shrubL, can be classified as light, moderate, and heavy grazing pressure regimes, respectively.

In spite of similar ger and livestock numbers (3 ger and $\sim 600$ heads), Sshrub showed a larger inedible plant fraction (33\%) than Bshrub (5\%). Moreover, inedible plants at Sshrub were broadly distributed, and plant coverage and height along the transect were lower than those at Bshrub. We infer two contrasting mechanisms to explain these differences in plant composition and spatial distribution at Bshrub and Sshrub. First, as noted above, camels and horses at the latter site can cause greater trampling and grazing pressure per head than sheep and goats. Second, because of its high biomass and nitrogen content, new branches of Caragana spp. can be attractive resources during spring and early summer before awn emergence in July (Jigjidsuren and Johnson 2003; Narantsetseg et al. 2014), which may reduce grazing pressure on herbaceous plants at Bshrub. Edible shrubs such as Caragana spp. may be important in pastureland sustainability by dispersing grazing pressure in normal years and providing critical foraging resources in drought periods, because of their greater

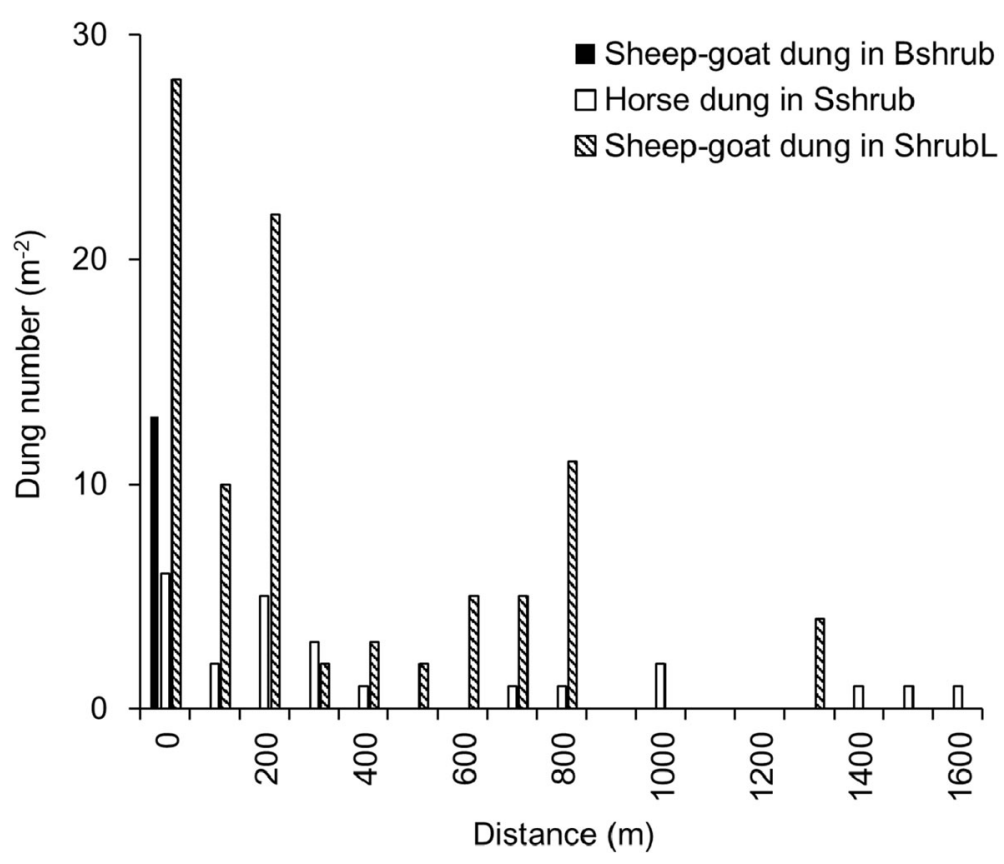

Fig. 4 Livestock dung number along transect from the wells at three study sites 
drought tolerance. As noted by Fujita et al. (2012), during drought periods, Caragana spp. are more actively grazed than herbaceous plants. This is because the former retains green aboveground biomass, while the latter maintains less aboveground biomass but stores more photosynthetic products in belowground parts.

It was interesting to discover certain meaningful spatial variations of herbaceous plant biomass along the transects. We found that biomass decreased with distance at shrubL but increased at Bshrub. Fernandez-Gimenez and Allen-Diaz (1999), however, reported no clear relationships between biomass and distance from wells in arid grasslands of Mongolia. The contrasting spatial patterns of plant biomass may have been caused by site-specific interactions of several ecological processes at landscape scales: (1) heavy selective grazing of livestock, increasing inedible plants; (2) livestock-driven centripetal nutrient translocation, increasing soil nitrogen content near the wells (Stumpp et al. 2005); (3) soil nitrogen enrichment caused by efficient nitrogen-fixing plants (such as Caragana spp.) (Cui et al. 2010); and (4) dispersion of grazing pressure by edible shrubs. Apparently, the first two processes explain the substantial biomass near the well at shrubL, but the last two explain the considerable biomass in remote pasture of Caragana spp. at Bshrub. Although process-level evaluation remains a subject of future study, the present investigation suggests selective grazing, grazing dispersion, and soil nitrogen enrichment as drivers of the diverse spatial biomass patterns in arid grassland landscapes.

\section{Conclusions}

Our vegetation classification based on plant edibility and morphology revealed spatial patterns indicating grazing and trampling effects on plant communities along transects and between sites. Dominant plants varied from inedible to edible plants along the transects, and the fraction of inedible plants and location of the transition zone varied by site. From site comparisons, fractions of grazing-tolerant, trampling-tolerant, and edible plants were related to heavy, moderate, and light livestock pressures, respectively at shrubL, Sshrub, and Bshrub. It appears that livestock numbers and composition and concomitant edible shrubs are important influences on the plant community. Our study provides some phenomenological findings regarding livestock grazing and tramping effects on plant communities, but some key questions concerning underlying temporal and spatial ecological mechanisms (e.g., grazing dispersion and nitrogen translocation) remain for future study.

\section{Abbreviations}

BS: Big shrub plant group; Bshrub: A name of site with big shrubs; EH: Edible herbaceous plant group; GE: Short-height gazing escape plant group;

GT: Grazing-tolerant plant group; GTH: Tall grazing-tolerant herbaceous plant group; shrubL: A name of site without shrubs; SS: Small shrub plant group;

Sshrub: A name of site with short shrubs

\section{Acknowledgements}

We sincerely thank Jaebeom Kim and Jongho Park from Kangwon National University and Sungwon Park and Dowon Lee from Seoul National University for their contribution in collecting the field data. We also would like to thank the Institute of General and Experimental Biology, Mongolian Academy of Science, for providing space and experimental equipment for vegetation sample treatment

\section{Funding}

This work was supported by research grants from the Korea Forest Service (S211212L06301), Korea National Research Foundation (C1013479-01-01), and Kangwon National University.

\section{Authors' contributions}

AN and SK undertook the statistical analysis and drafted the manuscript. DK participated in collecting the field data and drafting the manuscript. All authors read and approved the final manuscript.

Ethics approval and consent to participate

Not applicable

Consent for publication

Not applicable

\section{Competing interests}

The authors declare that they have no competing interests.

\section{Publisher's Note}

Springer Nature remains neutral with regard to jurisdictional claims in published maps and institutional affiliations.

\section{Author details \\ ${ }^{1}$ Institute of General and Experimental Biology, Mongolian Academy of Sciences, Ulaanbaatar, Mongolia. ${ }^{2}$ Department of Environmental Science, Kangwon National University, Chuncheon 200-701, Republic of Korea. ${ }^{3}$ Department of Forest Environmental System, Kookmin University, Seoul, Republic of Korea.}

Received: 8 December 2017 Accepted: 20 June 2018

Published online: 04 July 2018

\section{References}

Bedunah, D., \& Schmidt, S. (2000). Rangelands of Gobi Gurvan Saikhan National Conservation Park, Mongolia. Ranglands, 22, 18-24.

Bruegger, R. A., Jigjidsuren, O., \& Fernandez-Gimenez, M. E. (2014). Herder observations of rangeland change in Mongolia: indicators, causes, and application to community-based management. Rangeland Ecology \& Management, 67, 119-131.

Cérénhand, G. (2005). Mongolčuud: ugsaa-soël, zan zanšil 2. Ulaanbaatar, Mongolia: "ADMON" Press.

Cole, D. N. (1995). Experimental trampling of vegetation. II. Predictors of resistance and resilience. Journal of Applied Ecology, 32, 215-224.

Cui, Q., Lu, X. T., Wang, Q. B., \& Han, X. G. (2010). Nitrogen fertilization and fire act independently on foliar stoichiometry in a temperate steppe. Plant and Soil, $334,209-219$.

Fernandez-Gimenez, M. E., \& Allen-Diaz, B. (1999). Testing a non-equilibrium model of rangeland vegetation dynamics in Mongolia. Journal of Applied Ecology, 36, 871-885.

Fujita, N., \& Amartuvshin, N. (2012). Distribution patterns of vegetation as a fundamental factor in Mongolian ecosystems. In Yamamura et al. (Eds.), The Mongolian ecosystem network: environmental issues under climate and social changes (pp. 23-29). Springer Japan: Ecological Research Monograph.

Fujita, N., Amartuvshin, N., \& Ariunbold, E. (2012). Vegetation interactions for the better understanding of a Mongolian ecosystem network. In Yamamura et al. (Eds.), The Mongolian ecosystem network: environmental issues under climate and social changes (pp. 157-184). Ecological Research Monograph, Springer Japan.

Fujita, N., Amartuvshin, N., Uchida, T., \& Wada, E. (2002). Biodiversity and sustainability of Mongolian herbaceous plants subjected to nomadic grazing. In Fujita et al. (Eds.), Sustainable watershed with emphasis on lake ecosystems (pp. 101-107). Novosibirsk: DIWPA Series 3, Nauka-Center. 
Grubov, V. I. (2001). Key to the vascular plants of mongolia. Volumes I and II, Plymouth: Science Publishers.

Jambal, S. (2013). Effect of grazing pressure on vegetation structure of Mongolian rangeland. Okayama: Ph.D Dissertation, Okayama University, Japan.

Jigjidsuren, S., \& Johnson, D. A. (2003). Forage plants of Mongolia. Ulaanbaatar, Mongolia: "ADMON" Press.

Morinaga, Y., Chuluun, J., \& Takatsuki, S. (2016). Effects of grazing forms on seasonal body weight changes of sheep and goats in north-central Mongolia: a comparison of traditional nomadic grazing and experimental sedentary grazing. International Journal of Pure and Applied Zoology, 4, 124-126.

Mudongo, E. I., Fynn, R. W. S., \& Bonyongo, M. C. (2016). Role of herbivore impact and subsequent timing and extent recovery periods in rangelands. Rangeland Ecology \& Management. https://doi.org/10.1016/..rama.2016.04.003.

Mysterud, A. (2006). The concept of overgrazing and its role in management of large herbivores. Wildlife Biology, 12, 129-141.

Narantsetseg, A., Kang, S., Lkhamsuren, B., \& Dongwook, W. K. (2014). Determinants of Caragana microphylla density distribution in the Mongolian steppe. Ecological Research. https://doi.org/10.1007/s11284-014-1173-y.

Narantsetseg, A., Kang, S., Lkhamsuren, B., Jang, K., \& Dongwook, W. K. (2015). Assessment of biotic and abiotic factors controlling herbaceous biodiversity in Mongolian steppes. Ecological Informatics, 29, 221-229.

Sasaki, T., Okayasu, T., Takeuchi, K., Undarmaa, J., \& Sanjid, J. (2005). Patterns of floristic composition under different grazing intensities in Bulgan, South Gobi, Mongolia. Grassland Science, 51, 235-242.

Stumpp, M., Wesche, K., Retzer, V., \& Miehe, G. (2005). Impact of grazing livestock and distance from water source on soil fertility in Southern Mongolia. Mountain Research and Development, 25, 244-251.

Van der Maarel, E. (1979). Transformation of cover-abundance value in phytosociology and its effects on community similarity. Vegetatio, 39, 97-114.

Xu, L., Freitas, S. M. A., Yu, F. H., Dong, M., Anten, N. P. R., \& Werger, M. G. A. (2013). Effects of trampling on morphological and mechanical traits of dryland shrub species do not depend on water availability. PLoS One, 8 , e53021. https://doi.org/10.1371/journal.pone.0053021.

Ready to submit your research? Choose BMC and benefit from:

- fast, convenient online submission

- thorough peer review by experienced researchers in your field

- rapid publication on acceptance

- support for research data, including large and complex data types

- gold Open Access which fosters wider collaboration and increased citations - maximum visibility for your research: over $100 \mathrm{M}$ website views per year

At BMC, research is always in progress.

Learn more biomedcentral.com/submissions 